УДК 616.25-002-089

DOI: 10.26435/UC.V0I2(35).414

\author{
Д.В. Вегнер
}

ГОО ВПО «Донецкий национальный медицинский университет имени М. Горького», Донецк

\title{
ТЯЖЕЛАЯ ТРАВМА ГРУДИ. О ПОСЛЕОПЕРАЦИОННОМ ДРЕНИРОВАНИИ ПЛЕВРАЛЬНОЙ ПОЛОСТИ
}

\begin{abstract}
Дренирование плевральной полости (ДПП) является обязательным, а зачастую и основным компонентом лечения большинства хирургических заболеваний органов грудной полости [1]. Целью ДПП является удаление из нее содержимого для расправления легкого на весь объем плевральной полости, восстановления жизненной емкости легкого, уменьшения болевого синдрома и предупреждения генерализации инфекционного процесса [1, 2]. ДПП применяется для ликвидации пневмоторакса, гемоторакса, гемопневмоторакса [2, 3]. Также дренированием заканчиваются все операции на плевральной полости [2].
\end{abstract}

Несмотря на то что в настоящее время ДПП считается одной из наиболее часто выполняемых хирургических манипуляций, вопросы методики установки дренажа, его конструкции, количества и точек введения остаются дискутабельными.

Первые сообщения о применении ДПП в лечении хирургических заболеваний органов грудной полости принадлежат Гиппократу, который предлагал использовать трубки из жести для оттока и промывания полости подогретым вином и маслом [4]. Длительное время именно открытое ДПП являлось единственным способом эвакуации гноя из плевральной полости [5].

Принцип водяного замка (water-seal) при ДПП первым описал Playfair в 1873 г [6]. В 1875 г. Gotthard Bülau ввёл в практику способ пассивногравитационного дренирования плевральной полости с водяным замком, который используется до настоящего времени с незначительными вариациями. Однако в хирургической практике ДПП начали выполнять только в 50-е годы прошлого века, когда оно пришло на смену пункции плевральной полости с аспирацией воздуха и крови через иглу [6].

Альтернативой пассивно-гравитационному ДПП в настоящее время выступает так называемое «сухое» дренирование плевральной полости (dry suction) с использованием одностороннего клапана, открывающегося в сторону атмос- феры и предотвращающего попадание воздуха обратно в плевральную полость [4]. Наиболее популярным является клапан Геймлиха (Heilmich valve или flutter valve), предложенный в 1965 г. [6], который до настоящего времени используется для дренирования пневмоторакса и лечения эмпиемы плевры [4]. Однако «сухое» дренирование недостаточно при густом гнойном экссудате [5].

Описано использование аспираторов с заданным уровнем разрежения, оптимизирующим ДПП [5]. Однако сообщается, что аспирация в послеоперационном периоде не имеет преимуществ перед гравитационным ДПП, за исключением тех случаев, когда сохраняется сброс воздуха по дренажу более 1 суток и при нерасправляемом более 3 суток легком [5].

Установлено, что неадекватная функция плеврального дренажа может быть обусловлена неправильно выбранной точкой для дренирования или поздним дренированием плевральной полости на фоне развившегося свернувшегося гемоторакса [31]. Неадекватное дренирование может не только не принести пользы, но даже усугубить патологическое состояние организма.

Осложнениями после ДПП могут быть повреждения диафрагмы, органов брюшной полости, сердца, органов средостения, структур корня легкого [2]. Следствием неадекватного дренирования или преждевременного удаления дренажей является потребность в многократных плевральных пункциях и повторных дренированиях. Возникающие при этом осложнения (инфицирование плевральной полости, ятрогенная травма лёгкого и др.), 39\% из которых требуют хирургического лечения, определяют пролонгацию периода госпитализации и нередко потерю трудоспособности [2].

В современной торакальной хирургии известно множество способов дренирования плев-

() Д.В. Вегнер, 2020

(c) Университетская Клиника, 2020 
ральной полости после торакотомии, различающихся по локализации установки дренажа, положению дренажной трубки в плевральной полости, способу удаления и возможности контроля патологического содержимого плевральной полости, величине давления в плевральной полости и ряду других параметров [2, 4].

Традиционно перед ушиванием торакотомной раны плевральную полость дренируют двумя дренажами - верхним газовым и нижним жидкостным. Дренирование плевральной полости верхним дренажом используют в тех случаях, когда при пункции плевральной полости газ продолжает поступать, герметизм плевральной полости отсутствует и легкое не расправляется. Обычно жидкостный дренаж устанавливают в VII-VIII межреберьях по задней подмышечной линии, газовый - во II межреберье по среднеключичной линии $[1,2]$. Газовый дренаж удаляют при уверенности в его проходимости в условиях достигнутого стойкого герметизма плевральной полости, при рентгенологически подтвержденном расправлении легкого [2].

Однако таковое ДПП не всегда является удовлетворительным. Возникновение остаточных полостей в верхнем этаже плевральной полости нередко после резекции нежизнеспособной (в частности размозжённой) верхней доли или после декортикации длительно неаэрированного травмированного лёгкого [5, 6]. Пункция или дренирование остаточных полостей под куполом плевры нередко затруднительны из-за риска повреждения подключичных сосудов. Также при традиционном дренировании под куполом плевры, над дренажом часто образуется скопление воздуха, который поступает из дефектов паренхимы лёгкого и скапливается в указанной зоне вне досягаемости дренажной трубки, внутриплевральная часть которой находится, как правило, ниже этого скопления. Такие скопления препятствуют полноценному расправлению оперированного лёгкого, особенно в случаях снижения его эластичности. Особую актуальность приобретает эта проблема при хирургическом лечении пациентов с травмой органов грудной полости, прежде всего тупой, сопровождаемой переломами ребер, с выраженным болевым синдромом. Боль в области повреждений ребер препятствует достаточно глубокому дыханию, что ведет к нерасправлению легкого и развитию осложнений.

Таким образом, традиционное дренирование плевральной полости двумя дренажами не всегда является достаточным. В 2007 г. Я.Г. Колкин и соавт. [7] предложили для профилактики образования остаточных полостей под куполом плевры установку дополнительного, третье- го дренажа, фиксируемого к внутренней передней поверхности грудной стенки (париетальной плевре) лигатурой. Однако способ не нашел широкого применения.

Таким образом, несмотря на значительное разнообразие способов ДПП, до настоящего времени результаты дренирования после торакотомных операций не всегда остаются удовлетворительными, что побуждает к поиску более результативных способов ДПП и разработки критериев выбора наиболее эффективного из них в каждом конкретном клиническом случае. Это и явилось целью настоящей работы.

\section{МАТЕРИАЛ И МЕТОДЫ}

Исследование основано на изучении результатов лечения 214 пациентов (127 (59,3\%) мужчин и 87 (40,7\%) женщин), которым была выполнена торакотомия по поводу травмы груди, - основная группа (ОГ). Возраст пациентов варьировал от 22 до 63 лет и составил в среднем 43,4ะ11,5 года. У 119 (55,6\%) пострадавших травма была средней тяжести, у 95 (44,4\%) - тяжелая.

Для сравнения были взяты результаты лечения 189 пациентов, ДПП у которых выполняли по традиционным методам. Возрастной, гендерный состав группы сравнения (ГС), характер повреждений и степень тяжести состояния были сопоставимы с таковыми пациентов ОГ.

В ГС для ДПП у всех 189 пациентов использовали способ дренирования плевральной полости двумя полихлорвиниловыми дренажами. Перед ушиванием торакотомной раны на коже грудной клетки в проекции II межреберья по среднеключичной линии выполняли разрез

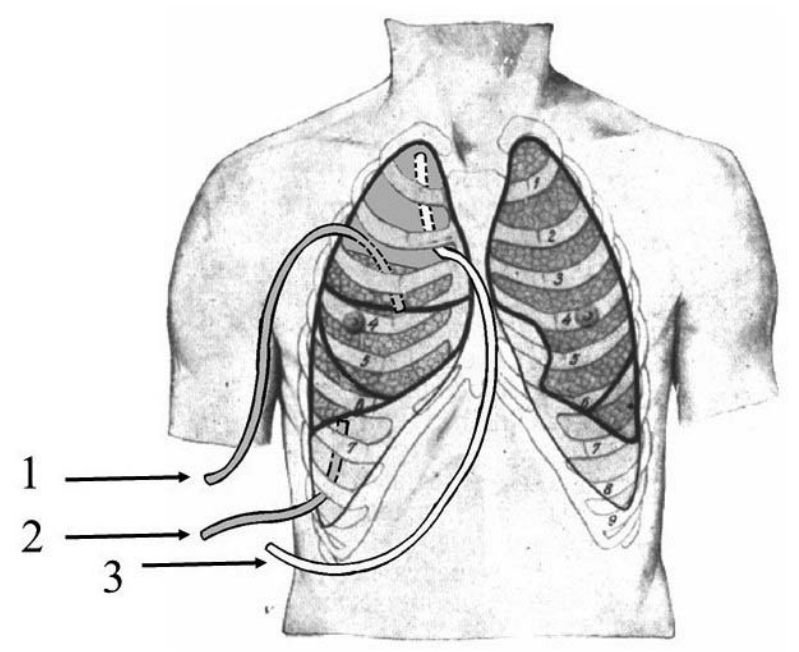

Рис. 1. Традиционное дренирование плевральной полости двумя дренажами $(1,2)$ с установкой дополнительного дренажа под купол плевры (3). 
кожи длиной до 1,0 см, глубиной - до подкожножировой клетчатки. В сформированный дефект кожи вводили зажим Микулича и проводили его в плевральную полость. В плевральной полости браншами зажима захватывали дренажную трубку и выводили ее на поверхность грудной клетки (рис. 1., 1), оставляя внутриплевральную часть дренажной трубки длиной около 10 см с отверстием диаметром $1 / 3$ от внутреннего диаметра трубки. Дренажную трубку фиксировали к коже отдельным узловым швом. Аналогичным образом устанавливали дренаж в проекции VII межреберья по задней подмышечной линии (рис. 1., 2). Вышеописанный способ дренирования рассчитан на выведение газа верхней дренажной трубкой и удаление жидкости нижней дренажной трубкой.

Учитывая, что недостатком этого способа является невозможность целенаправленно дренировать пространство в зоне купола плевры, при наличии факторов риска нерасправления легкого у $62(29,0 \%)$ пациентов для профилактики образования остаточной полости в верхних отделах использовали установку дополнительного дренажа по способу, предложенному Я.Г. Колкиным с соавт [7]. После проведения основного хирургического пособия и стандартного дренирования плевральной полости, перед ушиванием торакотомной раны на коже грудной стенки в I-II-м межреберье по среднеключичной линии производили разрез кожи 7-10 мм до подкожножировой клетчатки. Устанавливали дополнительный дренаж по вышеописанной методике. Длину внутриплеврального отрезка дренажной трубки определяли таким образом, чтобы он достигал купола плевры. Наружный отрезок дренажной трубки подшивали к коже, а внутриплевральную часть подводили к куполу плевры, где ее фиксировали к внутренней передней поверхности грудной стенки (париетальной плевре) лигатурой из биодеградирующего шовного материала. После фиксации дренажа (рис. 1., 3) торакотомную рану ушивали.

В основной группе всем 214 пострадавшим было проведено ДПП по оригинальной методике [8]. Технология ДПП отличалась от вышеописанной традиционной методики тем, что в плевральную полость устанавливали только один полихлорвиниловый дренаж собственной модификации, который отличался от ранее использовавшихся наличием множественных (до 8) перфораций внутриплевральной части дренажной трубки. Длина интраплевральной части дренажа была значимо больше таковой при стандартном дренировании - соответственно до 30 см и до 10 см. Дренаж размещали по всей внутренней поверхности задней грудной стенки и под- водили к куполу плевры до устья подключичной артерии. Внутриплевральную часть дренажа дополнительно к париетальной плевре не фиксировали (рис. 2.).

51 (23,8\%) пациенту ОГ при наличии факторов риска образования остаточных полостей в передне-верхних частях плевральной полости дополнительно был установлен второй дренаж

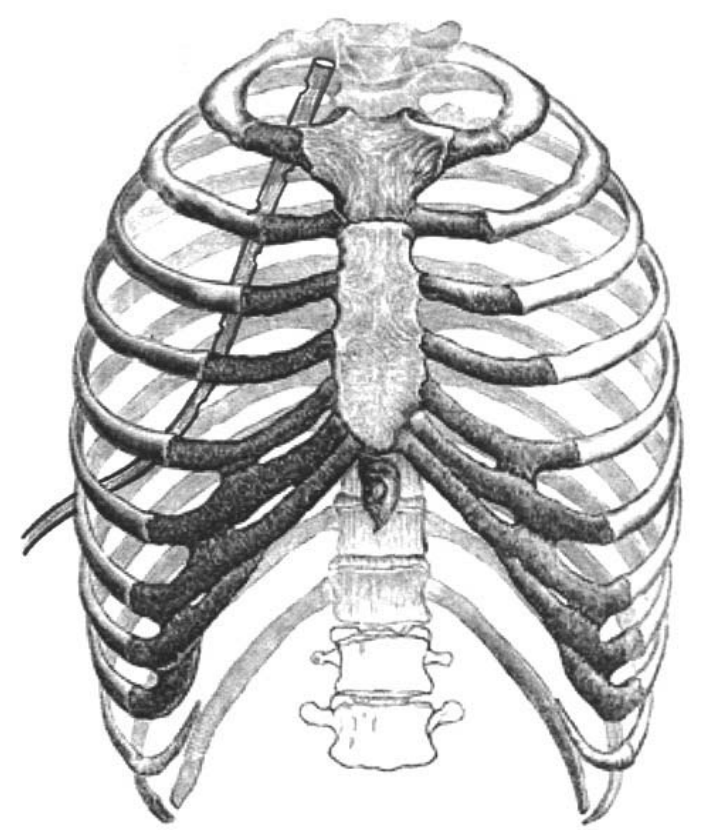

Рис. 2. Схема расположения дренажной трубки при собственном способе дренирования.

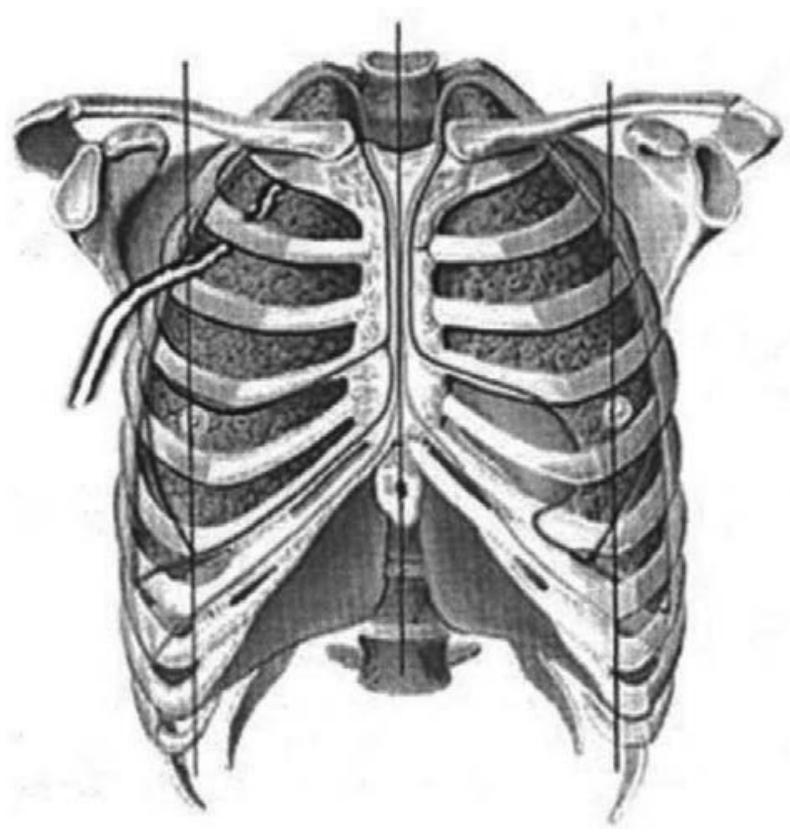

Рис. 3. Схема установки дополнительного дренажа для дренирования передне-верхних отделов плевральной полости. 
собственной модификации [9], который также отличался от ранее использовавшихся наличием множественных перфораций внутриплевральной части дренажной трубки. Установку дренажа выполняли по вышеописанной методике. Дренаж свободно располагали в грудной полости вдоль грудной стенки без дополнительной фиксации к париетальной плевре (рис. 3).

Факторами риска нерасправления легкого и образования остаточных полостей в обеих группах считали:

- значительный объем повреждений, множественные переломы ребер, сопровождающиеся выраженным болевым синдромом;

- наличие хронических специфических и неспецифических заболеваний легких, негативно влияющих на их эластичность и упругость.

Показанием для удаления дренажей было отсутствие сброса газа по дренажным трубкам.

Оценивали: длительность дренирования (с кратностью в 12 часов), количество случаев смещения дренажа с нарушением его функции, развитие осложнений, к которым относили формирование остаточной полости, бронхообтурационный синдром, пневмонию, абсцесс, эмпиему плевры. Также учитывали количество случаев, в которых в послеоперационном периоде потребовалась переустановка дренажа или дополнительное хирургическое лечение в объеме торакоскопии. Через 1, 3 и 5 суток после операции оценивали выраженность боли по субъективной визуально-аналоговой шкале, рекомендованной ВО3 (Huskisson, 1974 г.). Шкала предназначена для определения субъективного ощущения боли пациентом в момент исследования и объединяет сопряженные оценочные графы: графическую (пиктограммы лица с разным выражением), вербальную (описание выраженности боли), линейную без делений и количественную (в баллах - от 0 до 10).

Для показателей длительности дренирования и выраженности боли определяли диапазон и рассчитывали медианы значений. Полученные данные обрабатывались непараметрическими методами математической статистики с использованием следующих критериев: Фишера, медианного, $\chi^{2}$.

\section{РЕЗУЛЬТАТЫ И ОБСУЖДЕНИЕ}

Количество установленных дренажей в ОГ и ГС приведено в таблице 1.

При стандартном способе дренирования (ГС) в 127 (67,2\%) случаях устанавливали два дренажа в стандартных точках, в 62 (32,1\%) - дополнительный дренаж по Я.Г. Колкину (2007) (медиана количества дренажей - 2). В ОГ у большинства - 163 (76,2\%) пациентов - удалось ограничиться одним дренажом. Адекватность дренирования была обеспечена наличием множественных (7-8) перфораций внутриплевральной части дренажа, тогда как при традиционном дренировании количество отверстий в дренаже не превышало трех. В 51 (23,8\%) случае при прогнозируемом риске развития остаточных полостей возникла необходимость в установке дополнительного дренажа (медиана количества дренажей 1). Он также имел отличия в конструкции - 3 отверстия во внутриплевральной части по сравнению с традиционно используемым дополнительным дренажом, имеющим одно отверстие.

Таким образом, использование собственных инноваций, заключающихся в модификации основного и дополнительного дренажей в виде множественных перфораций интраплевральной части, обеспечивающих адекватное дренирование на протяжении, позволило статистически значимо ( $><0,001$, медианный критерий) сократить количество устанавливаемых дренажей. Тем самым достигнуто снижение травматизации тканей в местах установки дренажей, предрасполагающей к усилению боли, и сокращение продолжительности хирургического вмешательства до ушивания торакотомной раны.

Оценка выраженности болевых ощущений у пациентов, которым выполнено ДПП в ходе торакотомии (табл. 2.), позволила выявить ряд закономерностей.

Выраженность болевого синдрома на протяжении всего периода наблюдения значительно варьировала как в ОГ (диапазон включал 6 пунктов - от 4 до 9), так и в ГС (4 пункта - от 5 до

Количество установленных в ходе торакотомии дренажей у пациентов,

Таблица 1. оперированных по поводу травмы груди.

\begin{tabular}{ccccc}
\hline \multirow{2}{*}{ Количество дренажей } & \multicolumn{2}{c}{ Основная группа $(\mathrm{O \Gamma})$} & \multicolumn{2}{c}{ Группа сравнения (ГС) } \\
& Абс. & $\%$ & Абс. & \% \\
\hline \hline 1 & 163 & 76,2 & - & 189 \\
\hline 2 & 51 & 23,8 & 127 & 67,2 \\
\hline 3 & - & - & 62 & 32,1 \\
\hline
\end{tabular}


8). Данный факт обусловлен различиями внутри групп в характере и степени тяжести повреждений органов грудной клетки, переломов ребер, а также от индивидуальных особенностей субъективного восприятия боли. Однако медианы значений показателя боли имели статистически значимые отличия. Так, в ОГ медиана указанного показателя через 1 сутки после операции составила 5 баллов, в ГС - 7 баллов ( $\mathrm{p}=0,032$, медианный критерий). На протяжении всего периода наблюдения выявляли снижение медианы выраженности болевого синдрома: на 3 балла в ОГ и на $2-$ в ГС $(\mathrm{p}=0,024)$.

В ГС у одного из пациентов не наблюдали снижения выраженности боли, которую он на 1, 3 и 5 сутки оценил в 8 баллов, что определило неизменность верхней границы диапазона в группе. Однако у остальных пациентов наблюдали в различной степени выраженное (от 1 до 4 баллов) уменьшение боли, что отображает снижение медианы показателя в изучаемой группе с 7 до 5 баллов ( $\mathrm{p}=0,032)$.

В ОГ у всех пациентов наблюдали уменьшение болевых ощущений на 1-5 баллов. Следует отметить, что, несмотря на статистически значимые различия между группами в медианах показателя боли на каждом из этапов измерений, степень снижения изучаемого показателя в группах была однотипной и достоверно не различалась $\left(\chi^{2}=5,991, \mathrm{p}=0,0,793\right)$.

Таким образом, статистический анализ подтвердил достоверно меньшую выраженность болевого синдрома при дренировании по собственной методике по сравнению с традиционной. Данный факт, по нашему мнению, объясняется несколькими причинами.

Поскольку установка дренажа сама по себе является инвазивной процедурой, требующей повреждения грудной стенки, снижение количества установленных дренажей может объяснять меньшую выраженность боли в послеоперационном периоде, причем в группах имелись различия не только в количестве основных дре- нажей (как указывалось выше, один в основной и два в группе сравнения), но и в статистически значимой частоте потребности в дополнительном дренаже - соответственно 23,8\% и 29,0\% $(\mathrm{p}=0,23)$.

Следует также отметить, что различия в методике установки дополнительных дренажей также влияют на расхождения в выраженности болевого синдрома. Так, при традиционном способе дополнительная дренажная трубка устанавливается в I-II межреберье по среднеключичной линии, что ведет к травматизации мышечного слоя значительной толщины, хорошо снабженного нервными окончаниями. Дополнительный дренаж в ОГ устанавливали также через II межреберье, но по внешнему краю большой грудной мышцы, где мышечный слой минимален, что обусловило меньшую болезненность при стоянии дренажа.

Кроме того, при установке дополнительных дренажей в ГС для их фиксации производили прошивание париетальной плевры, что вело к дополнительной травматизации грудной стенки и усилению болевого синдрома. В ОГ фиксацию дренажей не производили.

Также в ГС чаще наблюдали развитие осложнений, описанных ниже. Воспаление при гнойно-септических процессах само по себе может выступать причиной, усиливающей боль в области повреждения, операционной раны и стояния дренажей. Таким образом, большее значение показателя боли в ГС может быть вызвано и большим количеством воспалительных осложнений.

При уменьшении выраженности боли снижается риск случайного смещения или удаления дренажа пациентом. Как в ОГ, так и в ГС рентгенологически определяли смещение дренажей из заданной зоны. Однако не всегда при смещении дренажа наблюдали ухудшение выведения газа и жидкости: в большинстве случаев функция дренажа не была нарушена и репозиция трубки не требовалась.

Динамика выраженности болевых ощущений в изучаемых группах

Таблица 2. (в баллах визуально-аналоговой шкалы)

\begin{tabular}{ccccc}
\hline & \multicolumn{4}{c}{ Выраженность боли, баллы } \\
\cline { 2 - 5 } Сроки после операции & Основная группа, $\mathrm{n}=214$ & \multicolumn{2}{c}{ Группа сравнения } \\
& ди=189 & медиана \\
\cline { 2 - 5 } & $4-9$ & медиана & диапазон & 7 \\
\hline \hline 1 сутки* $^{*}$ & $3-7$ & 4 & $5-8$ & 5 \\
\hline с суток* & $1-5$ & 2 & $4-8$ & 5 \\
\hline
\end{tabular}

Примечание: * - различия между ОГ и ГС статистически значимы при р<0,05 
При стандартном дренировании «газовая» дренажная трубка во II межреберье нередко смещалась от заданного положения, что в различной степени негативно влияло на адекватность

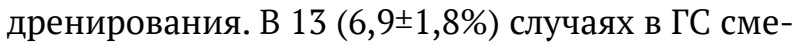
щение дренажа привело к полному нарушению его функции, что потребовало коррекции его

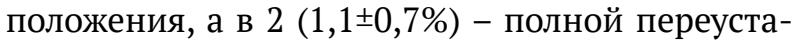
новки - дополнительной инвазивной манипуляции, болезненной для пациента. В ОГ случаев смещения с нарушением функции было всего $2(0,9 \pm 0,7 \%)$, что достоверно ( $\mathrm{p}=0,0017$, критерий $\left.\chi^{2}\right)$ меньше, чем в ГС; при этом для восстановления оттока по дренажу было достаточно репозиции. Оба эти случая были обусловлены беспокойным поведением пациента в связи с выраженным болевым синдромом. Меньшая частота смещения дренажа в ОГ обусловлена значимо большей длиной внутриплевральной части, чем при традиционном дренировании.

Отмечено, что в ГС, несмотря на используемую тактику профилактики посредством установки по показаниям дополнительного (третьего) дренажа, в 11 (5,8ะ1,7\%) случаях наблюдали формирование остаточных полостей: в $9(4,8 \pm 1,5 \%)$ - апикальных, в $2(1,1 \pm 0,7 \%)-$ в передне-верхних отделах.

По нашему мнению, формирование апикальных полостей обусловлено невозможностью целенаправленно дренировать пространство в зоне купола плевры, так как дренажная «газовая» трубка во II межреберье, которая предназначена для эвакуации газа из купола плевры, смещалась от требуемого расположения. В случаях, когда для профилактики апикальных полостей устанавливали третий дренаж, болевые ощущения в месте его установки и зоне прошивания париетальной плевры приводили к ограничению дыхательной экскурсии грудной клетки, что препятствовало расправлению легкого и способствовало развитию остаточных полостей. Наличие дополнительного дренажа также вызывало у пациентов дискомфорт, связанный с ограничением двигательной активности.

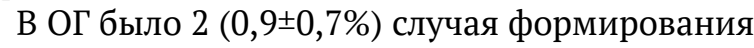
остаточной полости, что достоверно ( $<<0,01$, критерий $\chi^{2}$ ) меньше, чем в ГС; при этом полости были локализованы в передне-верхних отделах плевральной полости (у обоих пациентов дополнительный дренаж не устанавливали).

Кроме того, в ГС у $2(1,1 \pm 0,7 \%)$ пациентов в связи с неудовлетворительным дренированием и нерасправлением легкого видеоторакоскопически была выполнена декортикация легкого и рассечение спаек. В ОГ таких случаев не было.

Недостаточность дренирования и формирование остаточных полостей предрасполагали к развитию гнойно-воспалительных осложнений. Так, в ГС у $9(4,8 \pm 1,5 \%)$ пациентов наблюдали развитие отграниченной эмпиемы плевры, что существенно увеличивало сроки и стоимость лечения.

В ГС в результате дополнительной травматизации в процессе установки 2-3 дренажей и неадекватного в ряде случаев дренирования наблюдался более выраженный болевой синдром с нарушением биомеханики дыхания, что вело к ухудшению вентиляции легких, неблагоприятно влияющему на течение послеоперационного периода и потенцирующему развитие бронхообтурационного синдрома и пневмонии. Поскольку при установке одного дренажа у пациентов менее выражен послеоперационный болевой синдром, у них было меньше препятствий к нормализации экскурсии грудной клетки и улучшению вентиляции легких. Так, количество случаев развития бронхообтурационного синдрома в ГС - $12(6,3 \pm 1,8 \%)$ - статистически значимо ( $\mathrm{p}=0,046$, критерий $\left.\chi^{2}\right)$ превышало таковое

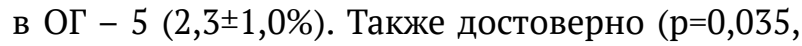

Количество осложнений и корригирующих мероприятий у пациентов

Таблица 3. с травмой грудной клетки после дренирования плевральной полости

\begin{tabular}{|c|c|c|c|c|}
\hline \multirow{2}{*}{ Параметр } & \multicolumn{2}{|c|}{ Основная группа, $\mathrm{n}=214$} & \multicolumn{2}{|c|}{ Группа сравнения, $\mathrm{n}=189$} \\
\hline & Абс. & $\%$ & Абс. & $\%$ \\
\hline "Смещение дренажа с нарушением его функции* & 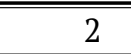 & $0,9 \pm 0,7$ & 13 & $6,6 \pm 1,8$ \\
\hline Формирование остаточной полости *** & 2 & $0,9 \pm 0,7$ & 11 & $5,8 \pm 1,7$ \\
\hline Бронхообтурационный синдром* & 5 & $2,3 \pm 1,0$ & 12 & $6,3 \pm 1,8$ \\
\hline Пневмония & 14 & $6,5 \pm 1,7$ & 24 & $12,7 \pm 2,4$ \\
\hline Отграниченная эмпиема плевры* & 2 & $0,9 \pm 0,7$ & 9 & $4,8 \pm 1,5$ \\
\hline Потребовалась переустановка дренажа & - & - & 4 & $2,1 \pm 1,0$ \\
\hline Потребовалась торакоскопия & - & - & 2 & $1,1 \pm 0,7$ \\
\hline
\end{tabular}

Примечание: различия между ОГ и ГС статистически значимы при: * - <<0,05; ** - p<0,01 
критерий $\left.\chi^{2}\right)$ чаще в ГС по сравнению с ОГ наблюдали развитие пневмонии: соответственно $24(12,7 \pm 2,4 \%)$ и $14(6,5 \pm 1,7 \%)$.

Количественные характеристики вышеописанных осложнений и выполненных корригирующих мероприятий обобщены в таблице 3.

Наличие вышеописанных осложнений влияло на длительность дренирования, которая в ОГ и ГС также различалась.

Так, в ОГ сроки стояния дренажей варьировали от 24 до 72 часов, медиана составила 48 часов. Максимальная длительность дренирования в ОГ (72 часа) зафиксирована вследствие продолжающегося сброса газа по дренажу у пациента с буллезной эмфиземой легкого, развившейся после резекции верхней доли в результате негерметичности шва легкого.

В ГС длительность стояния дренажей была значимо выше - от 36 до 96 часов, медиана - 72 часа ( $<<0,001$, медианный критерий). Сокращение сроков стояния дренажей в ОГ достигнуто за счет более адекватного дренирования, создания условий для максимально полного выведения отделяемого и сброса газа, а также минимизации гнойно-воспалительных осложнений.

\section{З АКЛЮ ЧЕНИЕ}

Проведенные исследования показали, что дренирование одним дренажом модифицированной конструкции (имеющим множественные перфорации внутриплевральной части) является методом выбора при торакотомных операциях по поводу травмы груди. При прогнозируемом риске развития остаточных полостей рекомендовано устанавливать дополнительный дренаж во II межреберье по внешнему краю большой грудной мышцы. Такой подход позволяет уменьшить выраженность болевого синдрома, сократить количество случаев формирования остаточной полости на 4,9\%, т.е. в 6,2 раза, значимо снизить количество гнойно-воспалительных осложнений. Применение предложенных инноваций позволило уменьшить длительность стояния дренажа в среднем на 24 часа, исключить потребность в переустановке дренажа или торакоскопической коррекции последствий неадекватного дренирования.

\section{Д.В. Вегнер \\ ГОО ВПО «Донецкий национальный медицинский университет имени М. Горького», Донецк}

\section{ТЯЖЕЛАЯ ТРАВМА ГРУДИ. О ПОСЛЕОПЕРАЦИОННОМ ДРЕНИРОВАНИИ ПЛЕВРАЛЬНОЙ ПОЛОСТИ}

Традиционное дренирование плевральной полости не всегда является достаточным ввиду формирования остаточных полостей и риска развития гнойновоспалительных осложнений. Целью работы явилась разработка более результативных способов дренирования плевральной полости после торакотомных операций.

Изучены результаты дренирования плевральной полости по собственным методикам у 214 пациентов после торакотомии по поводу травмы груди и по традиционным методикам - у 189 пациентов. Собственные инновации заключались в установке в плевральную полость одного полихлорвинилового дренажа собственной модификации - его интраплевральная часть характеризовалась значительной длиной (до 30 см) и наличием множественных перфораций. Факторами риска образования остаточных полостей в передне-верхних частях плевральной полости считали выраженный болевой синдром при значительном объеме повреждений и наличие хронических заболеваний легких, снижающих их эластичность и упругость. При наличии таковых (в 23,8\% случаев) дополнительно был установлен второй дренаж собственной модификации, который размещали через II межреберье по внешнему краю большой грудной мышцы, где мышечный слой минимален, без фиксации к париетальной плевре.
Установлено, что использование собственных инноваций обеспечивало адекватное дренирование на протяжении, что позволило достоверно снизить выраженность болевого синдрома по сравнению с традиционным дренированием: медиана выраженности боли составила на 1-е сутки после операции соответственно 5 и 7 баллов, на 5-е - 2 и 5 баллов.

Дренирование по собственной методике позволило достоверно уменьшить риск репозиции дренажа с нарушением его функции с $6,9 \%$ до $0,9 \%$, сократить количество случаев формирования остаточных полостей в апикальных и передне-верхних отделах плевральной полости с 5,8\% до 0,9\%, снизить количество гнойно-воспалительных осложнений с 17,5\% до 7,4\%, уменьшить длительность стояния дренажа в среднем на 24 часа, исключить потребность в переустановке дренажа или торакоскопической коррекции последствий неадекватного дренирования.

совершенствование способов дренирования плевральной полости после торакотомных операций и модификация используемых дренажей позволили сократить длительность дренирования и значимо снизить количество осложнений.

Ключевые слова: дренирование плевральной полости, травма груди, торакотомия. 


\section{D.V. Vegner}

\section{SEI HPE «M. Gorky Donetsk National Medical University», Donetsk}

\section{SEVERE THORACIC INJURY. POSTOPERATIVE PLEURAL CAVITY DRAINAGE}

The traditional pleural cavity drainage is not always sufficient as there might be the formation of residual cavities and the development of purulent and inflammatory complications. The aim of the work is to create more effective methods of pleural cavity drainage after thoracotomy operations.

The results of drainage in 214 patients using our own methods and in 189 patients using the traditional methods have been investigated. Our own innovation implied the setting of PVC drainage of proper modification into the pleural cavity. Its intrapleural part was chararterized by a significant length (up to $30 \mathrm{~cm}$ ) and the presence of multiple perforations. The risk factors of residual cavities formation in anterior and upper parts of the plural cavities were an intense pain syndrome due to a great number of injuries and the presence of the chronic lung disease decreasing their elasticity and flexibility. Taking the above mentioned into consideration (in $23,8 \%$ of cases), the second drainage of proper modification was set up additionally. That was performed through II intercostal space along the external border of the pectoral muscle where the muscular layer is minimal, without being fixed to parietal pleura.
It has been established that the use of our own innovations provided the adequate in duration drainage. It allowed to decrease reliably the intensity of the pain syndrome compared to the traditional methods: the median of pain intensity on the 1st day after the operation was 5-7 points, on the 5th day 2-5 points correspondingly.

Our methods allowed to decrease reliably the risk of drainage reduction with its function disturbance from $6,9 \%$ to $0,9 \%$, decrease the formation of residual cavities in apical, anterior and upper parts of the plural cavity from $5,8 \%$ to $0,9 \%$, decrease the number of purulent and inflammatory complications from $17,5 \%$ to $7,4 \%$, decrease the duration of drainage for 24 hours on average, exclude the necessity to set it up again or thoracoscopic correction of inadequate drainage.

The improvement of methods of pleural cavity drainage after thoracotomy operations and the modification of the drainages used made it possible to reduce the duration of drainage and decrease significantly the number of complications.

Key words: pleural cavity drainage, thoracic injury, thoracotomy.

\section{ЛИТЕРАТУРА}

1. Хасанов А.Р., Коржук М.С., Ельцова А.А. К вопросу о дренировании плевральной полости и измерении внутриплеврального давления. Проблемы и решения. Coвременные проблемы науки и образования. 2017; 5: 70 .

2. Колкин Я.Г., Вегнер Д.В. Хирургия тяжелой травмы груди. Донецк: Лебедь, 2010. 236.

3. Zisis C., Tsirgogianni K., Lazaridis G., Lampaki S., Baka S., Mpoukovinas I., Karavasilis V., Kioumis I., Pitsiou G., Katsikogiannis N., Tsakiridis K., Rapti A., Trakada G., Karapantzos I., Karapantzou C., Zissimopoulos A., Zarogoulidis K., Zarogoulidis P. Chest drainage systems in use Annals of Translational Medicine. 2015; 3(3): 43. DOI: 10.3978/j. issn.2305-5839.2015.02.09.

4. Хасанов А.Р. Дренирование плевральной полости. Прошлое и настоящее. Современные проблемы науки и образования. 2017; 6: 126.

5. Coughlin S., Emmerton-Coughlin H., Malthane, R. Management of Chest Tubes after Pulmonary Resection: A Systematic Review and Meta-Analysis. Canadian Journal of Surgery. 2012; 55: 264-270. doi.org/10.1503/cjs.001411

6. Zisis C., Tsirgogianni K., Lazaridis G,. Lampaki S. Chest drainage systems in use. Annals of Translational Medicine. 2015; (3): 43. DOI: 10.3978/j.issn.2305-5839.2015.02.09

7. Василенко Л.І., Першин Є.С., Гюльмамедов С.І-О., Ступаченко Д.О., Сидоренко Ю.О. Патент Україна № 23933; 2006.

8. Висоцький А.Г., Вегнер Д.В., Гюльмамедов С.І., Колкін Я.Г., Ступаченко Д.О., Герасіменко О.В. Патент Україна № $66295 ; 2011$.

9. Колкін Я.Г., Висоцький А.Г., Вегнер Д.В., Ступаченко О.М., Філахтов Д. П. Сидоренко Ю.О. Патент Україна № $66949 ; 2012$.

\section{REFERENCES}

1. Khasanov A.R., Korzhuk M.S., Eltsova A.A. K voprosu o drenirovanii plevral'noj polosti i izmerenii vnutriplevral'nogo davlenija. Problemy i reshenija [Drainage of the pleural cavity and change of pleural pressure in unexpandable lung]. Sovremennye problemy nauki i obrazovanija. 2017; 5: 70 (in Russian).

2. Kolkin Ja.G., Vegner D.V. Hirurgija tjazheloj travmy grudi [Surgery for severe breast injury]. Doneck: Lebed', 2010. 236 (in Russian).

3. Zisis C., Tsirgogianni K., Lazaridis G., Lampaki S., Baka S., Mpoukovinas I., Karavasilis V., Kioumis I., Pitsiou G., Katsikogiannis N., Tsakiridis K., Rapti A., Trakada G., Karapantzos I., Karapantzou C., Zissimopoulos A., Zarogoulidis K., Zarogoulidis P. Chest drainage systems in use Annals of Translational Medicine. 2015; 3(3): 43. DOI: 10.3978/j. issn.2305-5839.2015.02.09.

4. Hasanov A.R. Drenirovanie plevral'noj polosti. Proshloe i nastojashhee [Drainage of the pleural cavity in the past and present]. Sovremennye problemy nauki i obrazovanija. 2017; 6: 126 (in Russian).

5. Coughlin S., Emmerton-Coughlin H., Malthane, R. Management of Chest Tubes after Pulmonary Resection: A Systematic Review and Meta-Analysis. Canadian Journal of Surgery. 2012; 55: 264-270. doi.org/10.1503/cjs.001411

6. Zisis C., Tsirgogianni K., Lazaridis G., Lampaki S. Chest drainage systems in use. Annals of Translational Medicine. 2015; (3): 43. DOI: 10.3978/j.issn.2305-5839.2015.02.09

7. Vasilenko L I., Pershin E.S., Gjul'mamedov S.I-O. Stupachenko D.O., Sidorenko Ju.O. Patent Ukraina № 23933; 2006 (in Ukrainian).

8. Vysockij A.G., Vegner D.V., Gjul'mamedov S.I., Kolkin Ja.G., Stupachenko D.O., Gerasimenko O.V. Patent Ukraina № 66295; 2011 (in Ukrainian)..

9. Kolkin Ja.G., Vysockij A.G., Vegner D.V., Stupachenko O.M., Filahtov D.P. Sidorenko Ju.O. Patent UkrainaNo 66949; 2012 (in Ukrainian). 